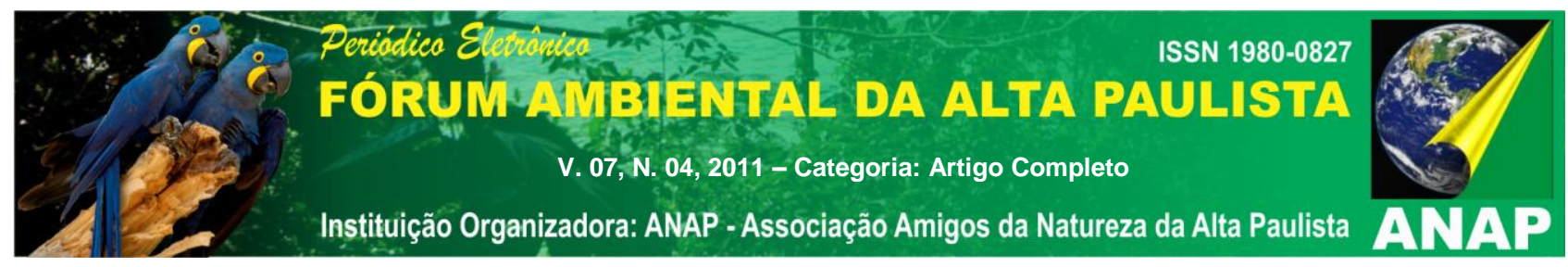

\title{
A POLÊMICA DA REDUÇÃO E EXTINÇÃO DO USO DAS SACOLAS PLÁSTICAS NOS SUPERMERCADOS
}

\author{
Dieli Tonello ${ }^{1}$ \\ Lilian Soares Guissoni ${ }^{2}$ \\ Marçal Rogério Rizzo ${ }^{3}$ \\ Sílvio Paula Ribeiro ${ }^{4}$ \\ Sirlei Tonello Tisott ${ }^{5}$
}

\begin{abstract}
Resumo: Este estudo visa identificar o nível de conscientização e as iniciativas dos consumidores e supermercadistas sobre o uso, redução ou extinção das sacolas plásticas. A base teórica do estudo está alicerçada em pesquisas pertinentes à problemática das sacolas plásticas e legislação pertinente. A pesquisa desenvolveu-se por meio de um levantamento - survey -, numa abordagem quantitativoqualitativa e descritiva, realizada no decorrer do mês de junho de 2011, junto a clientes e gestores de supermercados. Foram aplicados questionários a 203 pessoas, em dias e horários alternados, no intuito de atingir perfis diferenciados de consumidores, além de entrevistas semiestruturadas, direcionadas aos gestores, que enfatizaram seus pontos de vista sobre o tema. Em face dos objetivos, das diferentes fontes e dos instrumentos diferenciados de coleta de dados, a análise foi realizada por meio da triangulação. A maioria dos consumidores e todos os gestores dos supermercados são conscientes dos malefícios que o plástico pode causar ao meio ambiente e são favoráveis à redução e proibição das sacolas plásticas, no entanto o nível de conscientização em relação às atitudes não tem apresentado resultados significativos, tanto no grupo de consumidores, quanto no grupo de gestores. Além disso, os gestores apresentam barreiras quanto ao comprometimento e tendências gerencias. O estudo fornece contribuições e reflexões sobre a conscientização dos consumidores e dos gestores a uma problemática que está em crescente desenvolvimento e busca soluções efetivas.
\end{abstract}

Palavras chave: Sacolas plásticas. Ecobags. Resíduos sólidos.

\section{Introdução}

\footnotetext{
${ }^{1}$ Acadêmica do Curso de Ciências Contábeis, UFMS. dieli.tonello@hotmail.com.br

${ }^{2}$ Acadêmica do Curso de Ciências Contábeis, UFMS. lilianquissoni@yahoo.com.br

${ }^{3}$ Doutor em Geografia, UFMS. marcalprofessor@yahoo.com.br

${ }^{4}$ Mestre em Engenharia de Produção. UFMS. spribeiro@hotmail.com

${ }^{5}$ Mestre em Desenvolvimento, Gestão e Cidadania, UFMS. sirlei.tonello@yahoo.com.br
} 


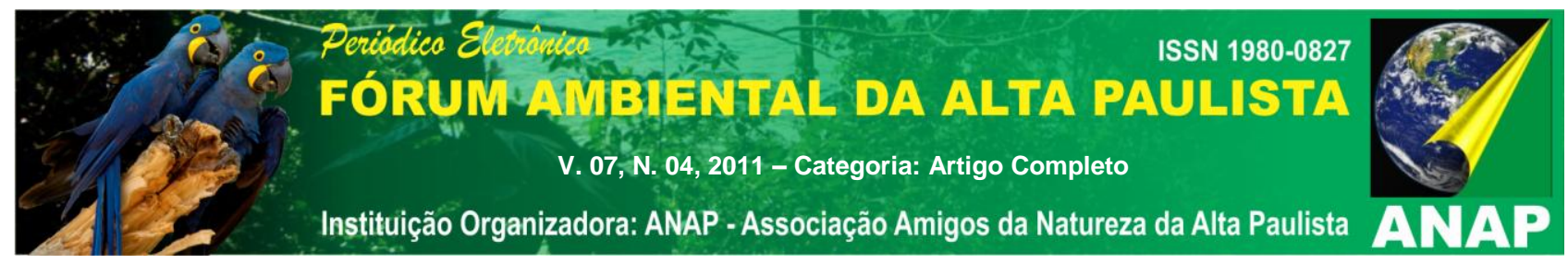

Nos últimos 30 anos, ocorreram grandes transformações no perfil dos consumidores, além de que a industrialização trouxe materiais a serem descartados, impactando no volume, quantidade, qualidade e composição do lixo. (GRIPPI, 2006). Com essas mudanças, vêm sendo produzidas e descartadas embalagens dos mais variados tipos: garrafas PET (politereftalato de etileno), copos descartáveis, caixas, sacolas de papel, sacolas plásticas, entre outros. As sacolas plásticas, quando utilizadas e descartadas de forma inadequada, tornam-se nocivas ao meio ambiente. Ao serem depositadas em lugares desapropriados, como aterros e lixões sem estrutura ecológica, podem ser carregadas pelo vento, contaminando rios, oceanos e lagos, e ocasionando a morte de diversas espécies de animais aquáticos ou terrestres.

Em conseqüência das mutações ocorridas na sociedade e dos impactos ambientais, estabeleceram-se diversas discussões, com pontos de vista favoráveis e desfavoráveis. Há os que são adeptos de abolir o uso de sacolas descartáveis, sobretudo em redes de supermercados, implantando assim o uso de ecobags ou sacolas retornáveis; há entidades que representam o setor de plástico e incentivam a continuidade do uso de sacolas plásticas, com ênfase no reuso e descarte, desde que não se agrida o meio ambiente (ROQUE, 2009); outros defendem o uso de sacolas de plástico oxibiodegradáveis, que vêm com um aditivo químico que acelera a decomposição, levando três anos para desaparecer; outros, ainda, defendem que o uso de ecobags é uma ilusão, tendo em vista que sua finalidade é desvirtuada: ao invés de as utilizarem para ir ao supermercado, os consumidores as usam mais como um acessório para passeio do que como medida de preservação ambiental. (DIAS, 2010).

Empresas fabricantes de plástico contestam a proibição desse produto, afirmando que "o plástico faz parte da vida contemporânea, é 100\% reciclável e está em milhares de produtos", além de haver tornado os automóveis mais leves e reduzindo a emissão de CO2, que é o principal agente causador do efeito estufa (PLANETA SUSTENTÁVEL, 2011). Apesar das divergências, há um ponto em comum nessa discussão: a necessidade de conscientização e atitude das pessoas para usar de forma racional e equilibrada esses recursos disponíveis. A redução dos índices de desastres ambientais acarretados pelo acúmulo de sacolas no meio ambiente dependem de ações educativas e comprometimento da população quanto ao descarte final do lixo. 


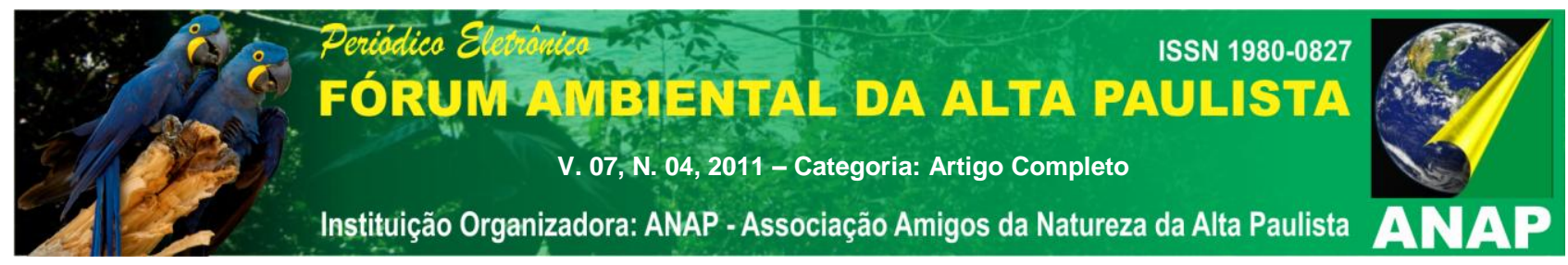

Os "temas sustentabilidade do planeta" e "preservação do meio ambiente" tornaram-se assuntos discutidos e difundidos tanto no meio acadêmico e organizacional, quanto nos meios de comunicação e na sociedade em geral. A Constituição Federal prevê que a preservação se faz necessária tanto pelo Poder Público quanto pela coletividade. "Todos têm direito ao meio ambiente ecologicamente equilibrado, bem de uso comum do povo e essencial à sadia qualidade de vida, impondo-se ao Poder Público e à coletividade o dever de defendê-lo para as presentes e futuras gerações" (BRASIL, 2010, art. 225).

Diante da problemática apresentada sobre as sacolas plásticas e do dever de preservar o meio ambiente, a pesquisa visa identificar o nível de conscientização e iniciativas da população e supermercadistas da cidade de Três Lagoas-MS sobre redução ou extinção do uso das sacolas plásticas.

\section{Resíduos sólidos: a problemática das sacolas plásticas}

Os resíduos sólidos são aqueles que se apresentam nos estados sólido e semissólido, originados pela indústria, hospitais, comércio, agricultura, serviços de varrição e lixo doméstico. Neste artigo aborda-se a problemática das sacolas plásticas.

A origem da palavra "plástico" é grega plastikós, que significa "adequado a moldagem", o que define a sua principal característica, a flexibilidade. O plástico é um dos materiais mais utilizados pelo homem, sendo sua principal matéria-prima o petróleo, também conhecido como termoplástico, por suas características de alta resistência, leveza e facilidade de modelagem industrial. Estima-se que "cerca de 4\% do petróleo mundial seja utilizado na produção de polímeros" - popularmente conhecidos como plástico (RIBEIRO; MORELLI, 2009, p. 63). O plástico apresenta várias identificações. O Polietileno de Baixa Densidade - PEBD, termoplástico número 4, é utilizado para a fabricação de sacos de lixo e embalagens flexíveis. No Brasil, a indústria do plástico apresenta números expressivos, com um consumo anual de mais de 4 milhões de toneladas de resinas termoplásticas, destinando-se $30 \%$ para a fabricação de embalagens. (GRIPPI, 2006).

Originadas desse tipo de matéria-prima, as sacolas plásticas, ao serem depositadas de maneira inadequada na natureza, são consideradas como vilãs ao meio ambiente, causando a morte de animais, entre os quais marinhos. Conforme estimativas 


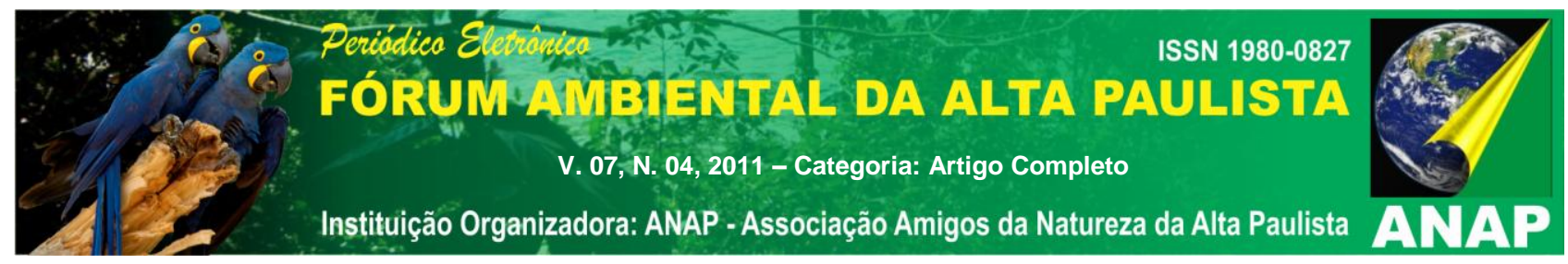

do Ministério do Meio Ambiente (2011), morrem por ano um milhão de animais marinhos. Outro problema que pode ser observado é o entupimento dos bueiros, dificultando o escoamento da água das chuvas. A impermeabilização de resíduos orgânicos nos lixões e nos aterros contribui para isolar o detrito do oxigênio e conduzir à putrefação, em vez de biodegradar. Em conseqüência disso, o resíduo vai apodrecer e liberar metano $(\mathrm{CH} 4)$, que tem grande potencial de aquecimento (OLIVEIRA, 2010). Os principais impactos à saúde, à segurança e ao meio ambiente identificados na reciclagem do plástico são alterações da paisagem, das condições dos corpos-d'água, da vida útil dos aterros, da qualidade dos lençóis freáticos, das emissões atmosféricas, do ruído e dos riscos à saúde pública e danos à saúde dos catadores (PEREIRA, 2006 apud FIGUEIREDO; DEORSOLAB, 2010).

$\mathrm{Em}$ face dessas considerações, existem controvérsias quanto ao uso ou proibição das sacolas plásticas, no entanto parece haver um consenso quanto ao impacto negativo que causam ao meio ambiente. Conforme dados obtidos no sítio do Ministério do Meio Ambiente (2011), 60\% dos consumidores são favoráveis à proibição das sacolas plásticas, no entanto, para que isso aconteça, é preciso o engajamento de todos os atores envolvidos - Poder Público, comércio e consumidores. Esse índice assinala a conscientização dos consumidores, mas, para mudar o comportamento das pessoas que acham a sacola essencial para o descarte do lixo doméstico, é preciso informar sobre o que fazer para eliminar o lixo e ter estrutura para recepcionar os resíduos. (ALBUQUERQUE, 2010).

O setor de plástico incentiva a continuidade do uso de sacolas plásticas com ênfase no reuso e descarte adequado (ROQUE, 2009). Para a Associação Brasileira da Indústria de Embalagens Plásticas Flexíveis - ABIEF (2011) e Instituto Socioambiental dos Plásticos - PLASTIVIDA, as sacolinhas são apontadas incorretamente como causadoras de impacto ambiental, mencionando que o problema não reside nelas e sim no desperdício e no descarte incorreto de uma parte das sacolas. Oliveira (2010) faz, no entanto, uma importante consideração quanto aos países em desenvolvimento, visto que a coleta de lixo ainda não é realidade em todo o seu território; faltam infraestrutura e políticas públicas para a gestão e gerenciamento do lixo. Além disso, é difícil falar em investimento na compra de sacos de lixo biodegradáveis quando existem milhões de pessoas famintas ou mal alimentadas. 


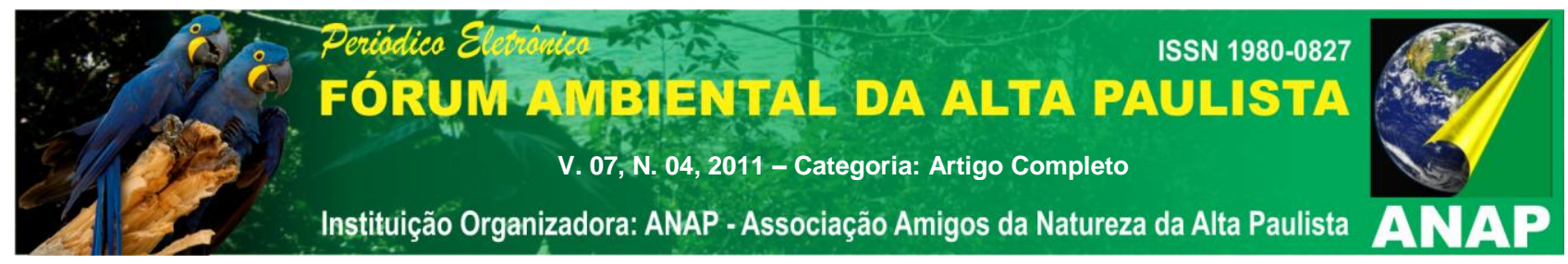

\subsection{Legislação sobre as sacolas plásticas}

No Brasil, várias são as iniciativas de municípios e estados que instituíram leis pertinentes à proibição do uso das sacolas plásticas, porém a aplicação de algumas foram suspensas por meio de medida liminar e outras passaram pelo Poder Legislativo, sendo vetadas pelo Poder Executivo. Conforme informações obtidas no sítio do Ministério do Meio Ambiente, a cidade de Belo Horizonte - MG é pioneira na criação de legislação para o assunto, em 2007. A determinação de substituição das sacolas plásticas por embalagens biodegradáveis entrou em vigor no ano de 2008, e, a partir de 2011, todos os estabelecimentos do município que não se adaptarem à Lei serão apenados, com multas e até mesmo a cassação do alvará de funcionamento do local. Seguindo o bom exemplo, outras cidades do país também adotaram leis sobre as sacolas plásticas, entre elas: Panambi/RS, Pouso Alegre/ MG, Florianópolis/SC, Sorocaba, Guarulhos e Jundiaí/SP, Belém/PA, Teresina/PI.

De acordo com Costa (2010), em Porto Alegre/RS, a lei, aprovada em abril de 2010, determina a impressão de conteúdo educativo sobre manejo de lixo nas sacolas plásticas para a separação de resíduos domésticos. Outro exemplo é o município de Uberaba/MG, que aprovou a lei proibindo o uso das sacolas plásticas, com substituição de $50 \%$ das sacolas comuns por alternativas ambientalmente adequadas (Câmara de Uberaba/MG).

A mobilização também acontece no âmbito do governo estadual, sendo o estado do Espírito Santo, o pioneiro, instituindo a lei estadual brasileira para o uso de sacolas plásticas no final de 2007, seguido pelos Estados do Paraná, Pernambuco, Distrito Federal e Maranhão. A mais recente lei estadual, no Rio de Janeiro, incentiva o consumidor a reduzir o uso de sacolas descartáveis, ao invés de apenas substituí-las por opções mais ecológicas, com incentivos de desconto de $R \$ 0,03$, na conta final do consumidor, a cada cinco produtos levados para casa sem o uso de sacolas plásticas e a distribuição de $1 \mathrm{~kg}$ de arroz ou feijão para cada consumidor que devolver ao supermercado 50 sacolas descartáveis usadas, que serão encaminhadas para reciclagem (PLANETA SUSTENTÁVEL, 2011). 


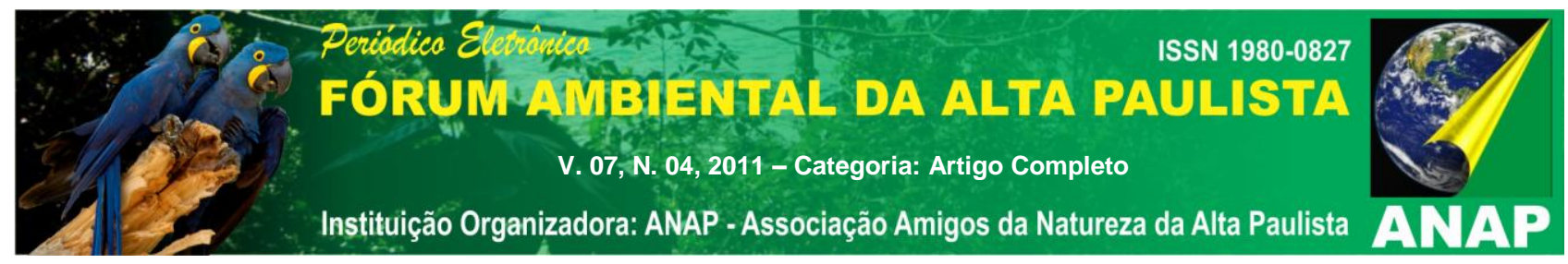

Diante dessas mobilizações políticas, observam-se resultados positivos quando analisados dados da pesquisa realizada em 2010, pelo Walmart Brasil e o Ministério do Meio Ambiente, com apoio do Instituto de Pesquisa Synovate do Brasil e da Envolverde, tendo em vista que $60 \%$ dos consumidores são favoráveis à lei que proíbe o uso das sacolas plásticas (MINISTÉRIO DO MEIO AMBIENTE, 2011). É preciso, no entanto, sair do campo teórico para a práxis, com atitude, conscientização, mobilização e execução de projetos que envolvam todos os atores (fabricantes das sacolas plásticas, Poder Público, comerciantes, consumidores e sociedade em geral).

\section{Procedimentos metodológicos}

Este estudo foi realizado por meio de um levantamento, numa abordagem quantitativo-qualitativa e descritiva. De acordo com Gil (2002, p. 50), nas pesquisas de levantamento "procede-se à solicitação de informações a um grupo significativo de pessoas acerca do problema estudado para, em seguida, mediante análise quantitativa, obterem-se as conclusões correspondentes aos dados coletados". As pesquisas descritivas têm como objetivo analisar características, levantar opiniões, atitudes e crenças de determinada população. (GIL, 2002).

O levantamento dos dados foi realizado considerando-se um corte longitudinal, no decorrer do mês de junho de 2011, junto a clientes dos seis maiores supermercados estabelecidos em Três Lagoas-MS. Os questionários foram aplicados a 203 pessoas, em dias e horários alternados, no intuito de atingir perfis diferenciados de consumidores. Tendo em vista que os pesquisadores não possuíam conhecimento prévio da população selecionada, foram utilizadas técnicas de amostragem não probabilística por conveniência e acessibilidade, com base na premissa de que "a seleção das unidades amostrais é deixada em grande parte a cargo do entrevistador [...], sendo que os entrevistados são escolhidos porque se encontram no lugar exato no momento certo". (MALHOTRA, 2004, p. 326).

De acordo com Mattar (2005, p. 157), na amostra não probabilística "não é conhecida a probabilidade de cada elemento fazer parte da amostra", portanto não permite ter controle sobre o erro amostral e não aceita a generalização dos dados obtidos para a população. Uma das razões para o uso da amostragem não probabilística é, 


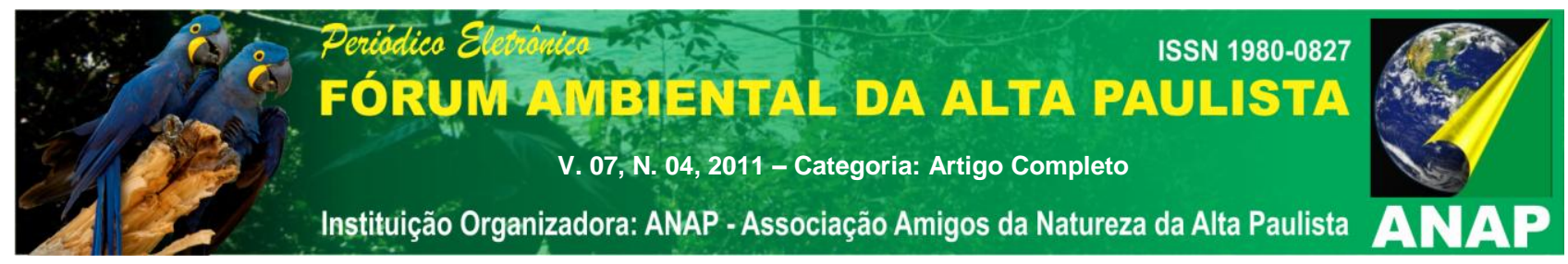

todavia, a não disponibilidade da população para ser sorteada, ou seja: os supermercados não dispõem de informações sobre seus clientes. Outra razão para o uso dessa amostragem refere-se às questões de limitação de tempo, recursos financeiros, materiais e pessoas disponíveis para a realização de uma amostragem probabilística. (MATTAR, 2005).

Para atingir o objetivo proposto, foram aplicadas, também, entrevistas semiestruturadas com gerentes e proprietários dos supermercados, que enfatizaram seus pontos de vista, de forma qualitativa, sobre o uso, redução ou extinção das sacolas plásticas. Os métodos qualitativos e os quantitativos podem ser associados em um mesmo estudo, de forma que diferentes perspectivas metodológicas complementam-se para a análise de um tema, destacando as convergências, diferenças ou combinações. (FLICK, 2009; CRESWELL, 2010). Isso equivale a dizer que um conjunto de dados qualitativos e quantitativos colaboram, em níveis de triangulação, para os resultados de uma pesquisa. Assim, a pesquisa baseou-se na triangulação dos dados, com o uso de diferentes fontes de dados obtidas a partir de pessoas diferentes e, na triangulação metodológica, com a combinação de instrumentos de coleta de dados diferentes questionários e entrevistas semiestruturadas. (FLICK, 2009).

\section{Resultados da pesquisa}

\subsection{Perfil dos consumidores e gestores dos supermercados}

Quanto ao perfil dos 203 consumidores participantes da pesquisa, 41\% são mulheres e 59\% homens. Entre eles, a predominância encontra-se nas faixas de 25 a 34 anos, 40 a 50 anos e 50 anos ou mais, conforme ilustrado na figura 1. Ainda se destaca, na figura 2, que $75 \%$ dos consumidores possuem ensino médio e ensino superior, um grau de escolaridade satisfatório para a formação de uma nova consciência voltada para a preservação do meio ambiente a partir da mudança de hábitos de consumo.
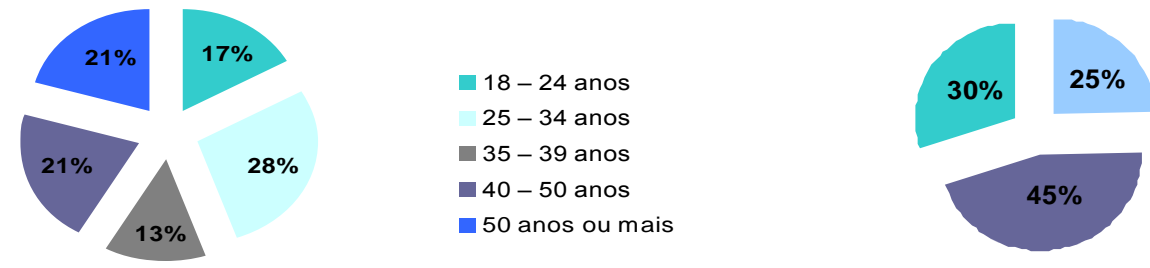


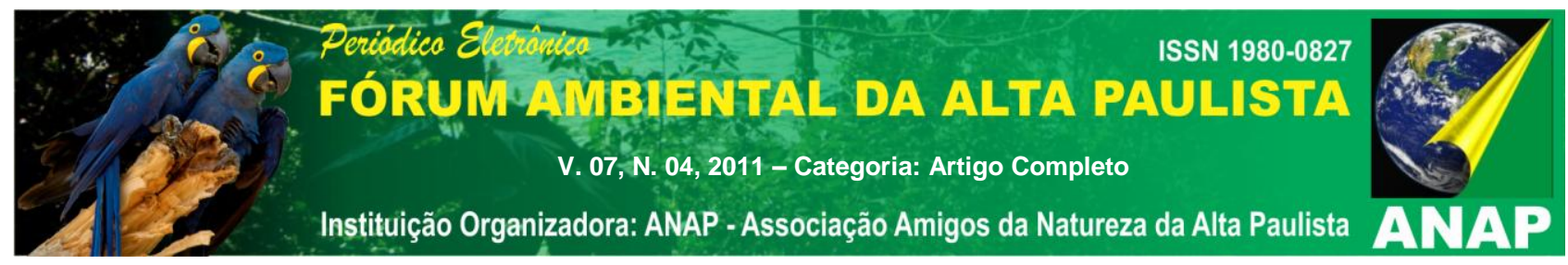

Figura 1 - Faixa etária dos consumidores

Figura 2 - Grau de escolaridade

\begin{tabular}{|c|c|c|}
\hline Gerentes & Grau de escolaridade & Atuação profissional \\
\hline A & Ensino médio completo & $\begin{array}{l}24 \text { anos no ramo de supermercados } \\
12 \text { anos no cargo de gerente }\end{array}$ \\
\hline B & $\begin{array}{l}\text { Ensino superior Administração, com } \\
\text { especialização na área de gestão de } \\
\text { supermercados }\end{array}$ & $\begin{array}{l}10 \text { anos no ramo de supermercados } \\
4 \text { anos no cargo de gerente }\end{array}$ \\
\hline C & Ensino superior em Administração & $\begin{array}{l}10 \text { anos no ramo de supermercados } \\
2 \text { anos no cargo de gerente }\end{array}$ \\
\hline $\mathrm{D}$ & Ensino médio completo & $\begin{array}{l}12 \text { anos no ramo de supermercados } \\
5 \text { meses no cargo de gerente }\end{array}$ \\
\hline E & $\begin{array}{l}\text { Ensino médio completo com cursos } \\
\text { profissionalizantes na área de recursos } \\
\text { humanos }\end{array}$ & $\begin{array}{l}20 \text { anos no ramo de supermercados } \\
4 \text { anos no cargo de gerente }\end{array}$ \\
\hline $\mathrm{F}$ & Ensino superior em Administração. & $\begin{array}{l}24 \text { anos no ramo de supermercado. } \\
22 \text { anos no cargo de gerente }\end{array}$ \\
\hline
\end{tabular}

Fonte: Dados da pesquisa, 2011.

Quadro 1 - Perfil dos gestores entrevistados.

O perfil dos gestores é composto exclusivamente por homens, com expressiva atuação profissional no ramo supermercadista, no entanto $50 \%$ deles possuem apenas o ensino médio. Um fator que deve ser superado com a capacidade investigativa no mundo dos negócios, aplicando a criatividade e ações de inovação, apresentando soluções e antecipando-se às situações impostas pelo ambiente organizacional.

\subsection{Conscientização dos consumidores sobre a problemática das sacolas plásticas}

Visando analisar o nível de conscientização dos consumidores sobre o uso, redução e extinção das sacolas plásticas, foi elaborado e aplicado um questionário, com o destaque de três variáveis: 1) conhecimento - reflexão, julgamento, opinião; 2) atitude efetividade; e 3) comprometimento - perspectivas dos consumidores.

$\mathrm{Na}$ tabela 1, ilustram-se os resultados da variável "conhecimento", que destaca uma significativa noção sobre os malefícios que as sacolas plásticas podem causar ao meio ambiente e campanhas desenvolvidas diante dessa problemática. Por outro lado, quando se trata de direitos e deveres garantidos e exigidos pela Constituição Federal do Brasil de 1988 sobre o uso e prevenção do meio ambiente, aproximadamente 54\% dos 


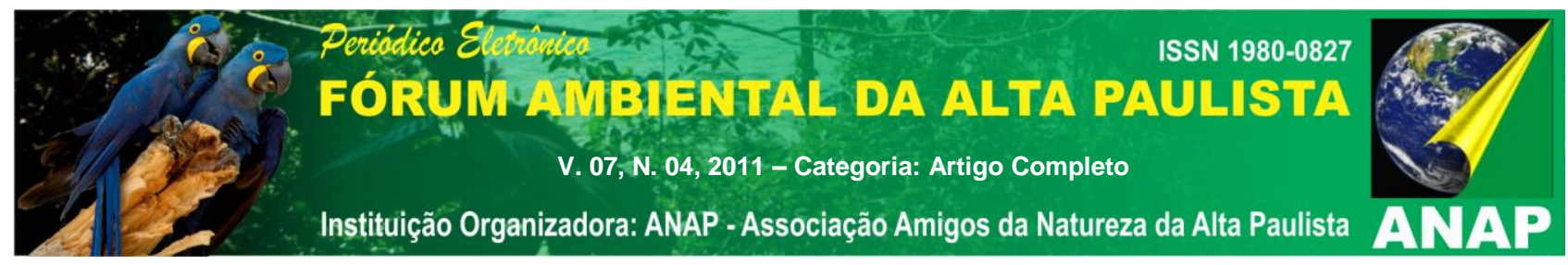

consumidores desconhecem essa legislação.

Tabela 1- Conhecimento, reflexão, julgamento e opinião dos consumidores

\begin{tabular}{lcc}
\hline Item/Questões & Quantidad & $\%$ \\
\hline 1. Você já ouviu falar em alguma campanha relacionada à redução do consumo de sacolas \\
- Sim & $\mathbf{1 8 2}$ & $\mathbf{8 9 , 6 6 \%}$ \\
- Não & 21 & $10,34 \%$ \\
\hline 2. Você conhece (ou já ouviu falar sobre) os malefícios que o plástico pode causar ao meio \\
- Sim & $\mathbf{1 9 4}$ & $\mathbf{9 5 , 5 7 \%}$ \\
- Não & 9 & $4,43 \%$ \\
\hline 3. Você conhece (ou já ouviu falar sobre) os direitos e deveres do Poder Público e coletividade \\
sobre o uso e prevenção do meio ambiente? & & \\
- Sim & $\mathbf{9 4}$ & $\mathbf{4 6 , 3 1 \%}$ \\
- Não & 109 & $53,69 \%$ \\
\hline 4. Quais são as três ações mais importantes que os supermercados podem realizar a favor do \\
- Não usar mais as sacolas plásticas & $\mathbf{1 1 4}$ & $\mathbf{2 0 , 7 7 \%}$ \\
- Ter estação de reciclagem nas lojas & $\mathbf{9 0}$ & $\mathbf{1 6 , 3 9 \%}$ \\
- Destacar produtos que ajudam a preservar o meio ambiente e & 66 & $12,02 \%$ \\
- Vender produtos que venham em embalagens recicláveis & 66 & $12,02 \%$ \\
- Campanhas para a utilização de sacolas retornáveis & $\mathbf{1 1 9}$ & $\mathbf{2 1 , 6 8 \%}$ \\
- Usar sacolas oxibiodeggradáveis & $\mathbf{9 4}$ & $\mathbf{1 7 , 1 2 \%}$ \\
\hline 5. Qual destas instituições é capaz de influenciar mais suas ações em relação ao meio & \\
- Escolas & $\mathbf{9 5}$ & $\mathbf{4 6 , 8 0 \%}$ \\
- Igrejas & 6 & $2,96 \%$ \\
- Comunidades & 11 & $5,42 \%$ \\
- Ong's & 5 & $2,46 \%$ \\
- Governo & 17 & $8,37 \%$ \\
- Mídia & $\mathbf{4 4}$ & $\mathbf{2 1 , 6 7 \%}$ \\
- Programas & 25 & $12,32 \%$ \\
\hline F & &
\end{tabular}

Fonte: Dados da pesquisa, 2011.

De acordo com os dados da pesquisa, as escolas e a mídia são as que possuem maior poder de influência positiva no desenvolvimento de ações ambientalmente corretas, conforme índices destacados na questão 5 da tabela 1. Para tanto, é importante que tanto as organizações públicas quanto as privadas utilizem escolas e mídias para potencializar mudanças em comportamentos agressivos e inadequados ao meio ambiente e à humanidade.

$\mathrm{Na}$ opinião dos respondentes, uma das ações mais importantes que os supermercados podem executar na gestão ambiental é o desenvolvimento de campanhas de conscientização para a utilização de sacolas retornáveis; em segundo lugar, com $20,77 \%$, abolir o uso das sacolas plásticas; em terceiro lugar, incorporar o uso de sacolas biodegradáveis; em quarto lugar, manter estação de reciclagem nos supermercados. Nesses quatro quesitos, observam-se sugestões para a gestão socioambiental dos supermercados que estejam comprometidos com a sustentabilidade e a minimização de 


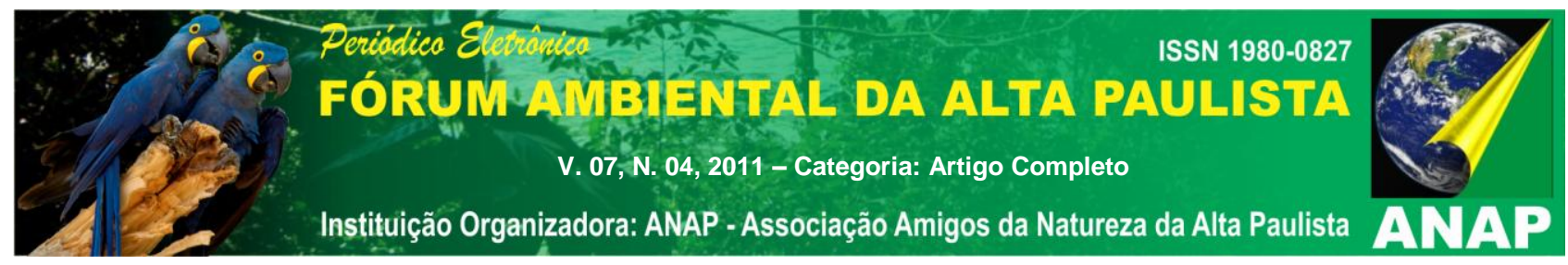

impactos ambientais. Diante disso, visualizam-se benefícios com a redução de custos na aquisição das sacolas plásticas e incremento de receitas com a venda de reciclados depositados nas estações, podendo esses valores ser investidos em projetos sociais, que poderão proporcionar ganhos de imagem corporativa e vantagens competitivas (ALIGLERI; ALIGLERI; KRUGLIANSKAS, 2009; TACHIZAWA, 2009; TACHIZAWA; ANDRADE, 2008).

Tabela 2 - Atitude dos consumidores

\begin{tabular}{lcc}
\hline Item/Questões & Quantidade & $\%$ \\
\hline 1. Você possui ecobag? (se sim, então responda à questão 2) & \\
• Sim & $\mathbf{7 1}$ & $\mathbf{3 4 , 9 8 \%}$ \\
• Não & 132 & $65,02 \%$ \\
\hline 2. Com que frequência você utiliza a sua ecobag? (se às vezes ou raramente, \\
então responda à questão 3) & \\
• Sempre & $\mathbf{1 8}$ & $\mathbf{2 5 , 3 5 \%}$ \\
- Às vezes & 19 & $26,76 \%$ \\
• Raramente & 34 & $47,89 \%$ \\
\hline 3. Quais são os motivos que o levam a utilizar a ecobag às vezes ou raramente \\
• Esquecimento & $\mathbf{4 0}$ & $\mathbf{7 5 , 4 7 \%}$ \\
- Pouca praticidade & 9 & $16,98 \%$ \\
- Utilizadas para outros fins & 4 & $7,55 \%$ \\
\hline 4. Você separa o lixo molhado (orgânico) do lixo seco (reciclável)? \\
• Sim & $\mathbf{1 0 9}$ & $\mathbf{5 3 , 6 9 \%}$ \\
• Não & 94 & $46,31 \%$ \\
\hline 5. Você utiliza as sacolas plásticas para descartar o lixo doméstico? & \\
• Sim & $\mathbf{1 8 3}$ & $\mathbf{9 0 , 1 5 \%}$ \\
• Não & 20 & $9,85 \%$ \\
\hline Fonte: Dados da pesquisa, 2011. &
\end{tabular}

A comparar a tabela 1 à tabela 2, observa-se que há um distanciamento entre as "boas intenções" (conhecimento) e a práxis (atitudes) das ações benéficas ao meio ambiente. Inicialmente, com base nos dados apresentados na tabela 1, nota-se que os consumidores possuem esclarecimentos sobre a problemática do consumo e destinação das sacolas plásticas, além de se destacarem importantes iniciativas gerenciais que podem ser implementadas pelo Poder Público e entidades privadas na promoção da educação ambiental, racionalização da utilização dos recursos naturais e na minimização de impactos ambientais.

Das pessoas que possuem ecobag, apenas $25 \%$ as utilizam efetivamente. Destaca-se, também, o alto índice de pessoas que usam as sacolas plásticas para descartar o lixo doméstico e um razoável grau de consciência sobre a coleta seletiva. Essas ações poderiam ser potencializadas caso houvesse maior empenho dos agentes 


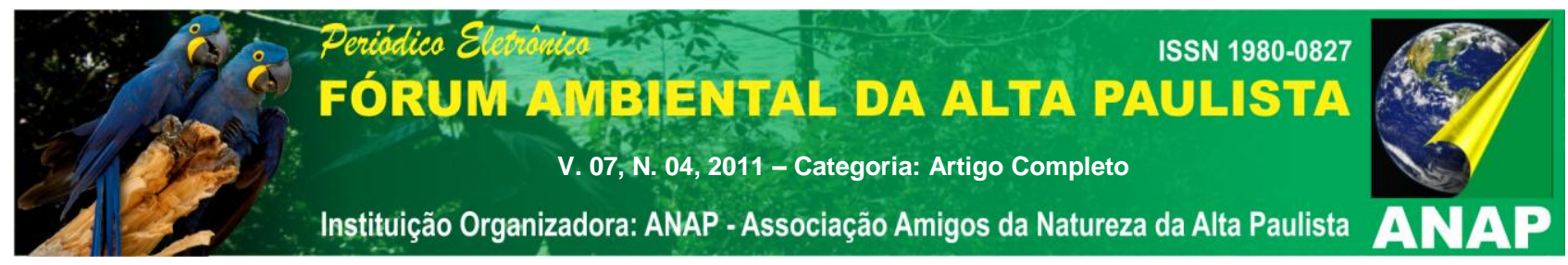

públicos e privados na coleta seletiva, implementação de estações de reciclagem e usinas de reciclagem, com a instituição de parcerias na troca do lixo reciclável por sacos de lixo e ecobags para a correta destinação dos resíduos domésticos e acondicionamento das compras.

Tabela 3 - Comprometimento e tendências comportamentais dos consumidores

\begin{tabular}{|c|c|c|}
\hline Item/Questões & Quantidade & $\%$ \\
\hline \multicolumn{3}{|c|}{ 1. Se existisse uma lei que proibisse a distribuição de sacolas plásticas você seria... } \\
\hline - Favorável & 168 & $82,76 \%$ \\
\hline - Contra & 17 & $8,37 \%$ \\
\hline - Indiferente & 18 & $8,87 \%$ \\
\hline
\end{tabular}

2. Se as sacolas plásticas desaparecessem do mundo, como carregaria as compras de supermercados? Marcar até 3 itens

- Sacolas de outro material

- Ecobag

$97 \quad 19,09 \%$

- Caixa

129

$25,39 \%$

- Carrinho

127

$25,00 \%$

- Bolsa

68

$13,39 \%$

- Não sabe

84

$16,54 \%$

3. Se as sacolas plásticas desaparecessem do mundo, onde depositaria o lixo e os resíduos

- Lixeira

87

- Caixa

43

- Sacolas de outro material

33

- Outros recipientes

31

- Não sabe

9

4. Se o supermercado cobrasse pelas sacolas plásticas, você pagaria por elas?

- Sim

- Não

162

$42,86 \%$

$21,18 \%$

$16,26 \%$

$15,27 \%$

$4,43 \%$

5. Você é favorável a abolir, definitivamente, o uso das sacolas plásticas em supermercados?

- Sim

176

$20,20 \%$

- Não

27

$86,70 \%$

Fonte: Dados da pesquisa, 2011.

Quanto ao comprometimento e tendências comportamentais dos consumidores, observam-se intenções positivas de adesão a leis que proíbem a distribuição das sacolas plásticas. Nas questões 2 e 3, constata-se uma adesão significativa à utilização de embalagens e recipientes alternativos para o acondicionamento das compras efetuadas nos supermercados e disposição do lixo doméstico.

Ao analisar conjuntamente as questões 1,4 e 5, ressalta-se que há um consenso entre as respostas obtidas, gerando uma relação de causa e efeito. A maioria é favorável à lei que proíbe a distribuição das sacolas plásticas, e, consequentemente, esses consumidores não se dispõem a pagar pelas sacolas plásticas, incentivando sua extinção definitiva nos supermercados. 


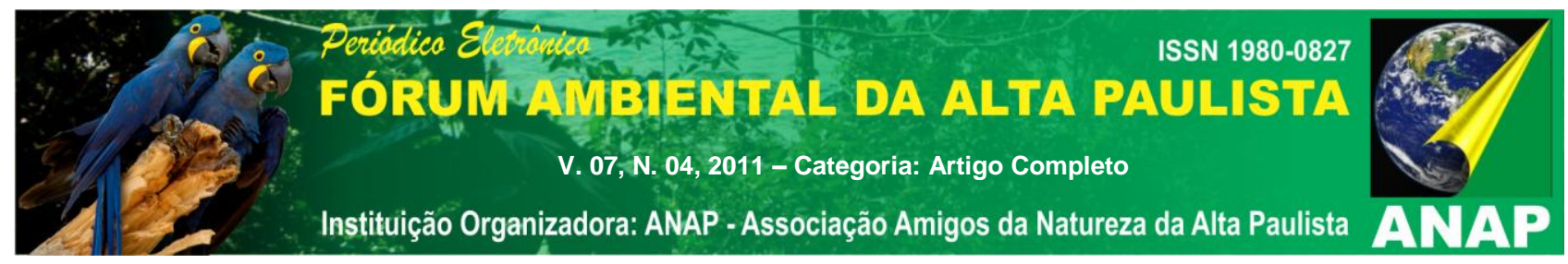

Em síntese, destaca-se que o resultado da pesquisa quantitativa expressa um bom nível de conhecimento, capacidade e disposição dos consumidores em relação à problemática do uso das sacolas plásticas e possíveis alternativas para minimizar os impactos negativos. Visualiza-se, no entanto, na variável atitude, baixo índice de conscientização dos consumidores com as práticas de sustentabilidade ambiental.

\subsection{Conscientização dos gestores sobre a problemática das sacolas plásticas}

Visando analisar o nível de conscientização dos gestores, foram realizadas entrevistas com seis gerentes de supermercados, que destacam seus conhecimentos, opiniões, atitudes, iniciativas e o comprometimento do supermercado em relação ao problema exposto.

Os gestores foram questionados quanto ao conhecimento que possuem sobre os efeitos maléficos das sacolas plásticas ao meio ambiente, e 100\% deles demonstram possuir esclarecimentos e são favoráveis às leis que proíbem o uso dessas embalagens. No quadro 2, destacam-se alguns comentários obtidos junto aos gestores dos supermercados.

\begin{tabular}{|c|l|}
\hline Gestor & Comentários e opiniões \\
\hline A & $\begin{array}{l}\text { Todos os funcionários estão conscientes dos malefícios que o plástico pode causar ao meio } \\
\text { ambiente, tanto que o supermercado é favorável a adotar campanhas ou leis para extinguir o uso } \\
\text { das sacolas plásticas. }\end{array}$ \\
\hline B & $\begin{array}{l}\text { Possui conhecimento sobre os danos causados pelo plástico ao meio ambiente quando } \\
\text { descartados inadequadamente e é favorável à institucionalização de leis e campanhas que } \\
\text { proíbam o uso das sacolas plásticas. }\end{array}$ \\
\hline C & $\begin{array}{l}\text { O gestor menciona que os malefícios causados pelas sacolas plásticas são divulgados com } \\
\text { frequência na mídia e está consciente sobre a gravidade dos impactos causados ao meio } \\
\text { ambiente. }\end{array}$ \\
\hline D & $\begin{array}{l}\text { Já ouviu muitos comentários sobre os danos que os plásticos causam ao meio ambiente e é } \\
\text { favorável à extinção das sacolas plásticas nos supermercados. }\end{array}$ \\
\hline E & $\begin{array}{l}\text { É a favor das leis que proíbem o uso das sacolas plásticas, tendo em vista o conhecimento que } \\
\text { possui sobre os danos que estas causam ao meio ambiente. }\end{array}$ \\
\hline F & $\begin{array}{l}\text { Possui noções sobre os malefícios por meio de campanhas veiculadas nos meios de } \\
\text { comunicação. Além disso, menciona que a extinção das sacolas plásticas somente se efetivará } \\
\text { quando for exigida por lei. }\end{array}$ \\
\hline
\end{tabular}

Fonte: Dados da pesquisa, 2011.

Quadro 2 - Comentários e opiniões dos gestores entrevistados.

\begin{tabular}{|c|l|}
\hline Gestor & Atitudes e iniciativas \\
\hline A & $\begin{array}{l}\text { Algumas iniciativas já foram tomadas com a oferta de sacolas ecológicas aos seus clientes a um } \\
\text { valor acessível, de } \mathrm{R} \$ 1,99 .\end{array}$ \\
\hline B & $\begin{array}{l}\text { Foi realizada uma campanha para incentivar os clientes a substituir as sacolas plásticas pelas } \\
\text { ecológicas e na compra de uma ecobag, o cliente estaria participando do sorteio de uma viagem. }\end{array}$ \\
\hline
\end{tabular}




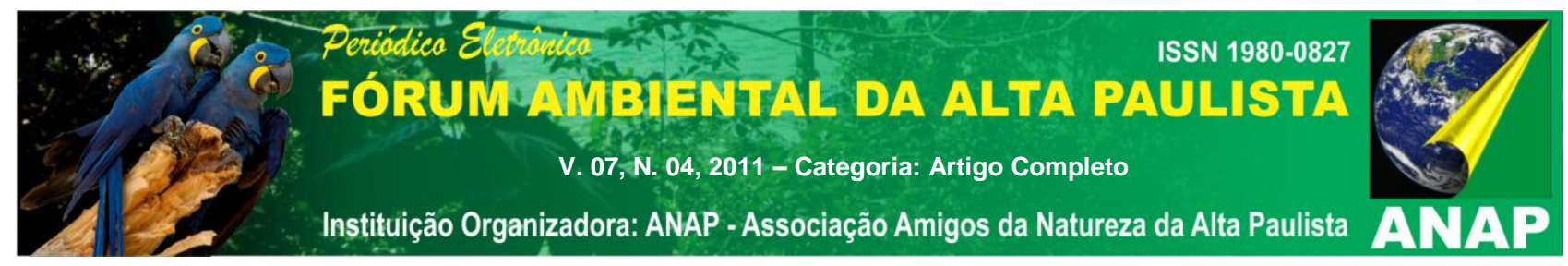

\begin{tabular}{|c|c|}
\hline & $\begin{array}{l}\text { A iniciativa não foi, no entanto, bem-sucedida em decorrência do valor cobrado ( } \mathrm{R} \$ 4,99) \text { por } \\
\text { ecobag, enquanto as sacolas plásticas não têm custo para os consumidores. } \\
\text { As sacolas ecológicas continuam sendo disponibilizadas para o cliente que quiser adquirir, porém } \\
\text { sem uma bonificação correspondente. }\end{array}$ \\
\hline C & $\begin{array}{l}\text { Utiliza sacolas oxibiodegradáveies, disponibiliza caixas para os clientes carregarem suas compras } \\
\text { e oferece ecobag para os clientes no valor de } R \$ 5,98 \text {. }\end{array}$ \\
\hline $\mathrm{D}$ & $\begin{array}{l}\text { Não desenvolve campanhas de conscientização dos clientes sobre o uso, problemática, redução e } \\
\text { extinção das sacolas plásticas, mas disponibiliza sacolas ecológicas para aqueles clientes que } \\
\text { querem adquiri-las, por um valor de } \mathrm{R} \$ 2,99 \text {. Além disso, disponibiliza meios alternativos para os } \\
\text { clientes carregarem suas compras em caixas de papel. }\end{array}$ \\
\hline$E$ & $\begin{array}{l}\text { Iniciativas adotadas: venda de sacolas ecológicas no valor de } \mathrm{R} \$ 1,99 \text {, disponibilização de caixas } \\
\text { de papelão e entrega em domicílio das mercadorias dos seus clientes nas caixas de plástico do } \\
\text { próprio supermercado. } \\
\text { Com tais iniciativas, o gestor menciona que, em toda a rede de supermercados, há uma redução } \\
\text { na utilização de sacolas plásticas de } 200.000 \text { unidades por mês. }\end{array}$ \\
\hline$F$ & $\begin{array}{l}\text { O gestor menciona que incentiva o uso de sacolas retornáveis, mas não as disponibiliza no } \\
\text { supermercado. Além disso, utiliza sacolas biodegradáveis e incentiva o uso de caixas de papelão. }\end{array}$ \\
\hline
\end{tabular}

No quadro 3, destacam-se as atitudes e iniciativas dos supermercados na gestão ambiental em relação ao uso, redução e extinção das sacolas plásticas, no entanto notase a realização de ações pouco estruturadas para que ocorra uma mudança efetiva.

Quanto ao comprometimento e tendências gerenciais, apresentam-se, no quadro 4, comentários efetuados pelos gestores dos supermercados.

\begin{tabular}{|c|l|}
\hline Gestor & Comprometimento e tendências gerenciais \\
\hline $\begin{array}{c}100 \% \text { dos gestores acreditam que os supermercados estão preparados para implementar mudanças caso } \\
\text { entre em vigor lei que próba a distribuição de sacolas plásticas. }\end{array}$ \\
\hline A & $\begin{array}{l}\text { As alternativas constituem-se em oferecer outros meios para que os clientes possam carregar } \\
\text { suas compras. O gestor acredita que iniciativas como campanhas de bonificação e } \\
\text { institucionalização de leis que proíbam o uso das sacolas plásticas seriam aceitas pelos } \\
\text { consumidores locais; além disso, podem atrair mais clientes para os supermercados. }\end{array}$ \\
\hline B & $\begin{array}{l}\text { Fornecer aos seus clientes outras opções para carregar suas compras, como caixas de papel, e, } \\
\text { se estas não fossem suficientes, introduziria outros meios que substituiriam o plástico, porém } \\
\text { levaria um tempo para que o mercado e os clientes possam adaptar-se a essas mudanças. } \\
\text { O gerente já ouviu falar de diversas campanhas em outros estados brasileiros em que os clientes } \\
\text { que levam sua ecobag para fazer as compras recebem desconto ou acumulam pontos para } \\
\text { receber prêmios, e acredita que tais iniciativas poderiam ser adotadas com seus clientes, no } \\
\text { entanto considera que não seria vantajoso, estimando que são poucos os clientes favoráveis à } \\
\text { extinção das sacolas plásticas. }\end{array}$ \\
\hline C & $\begin{array}{l}\text { É possível promover campanhas que bonifiquem os clientes, concedendo descontos nas compras } \\
\text { daqueles que levarem suas ecobags. Esse valor será economizado na aquisição das sacolas } \\
\text { plásticas, podendo ser repassado ao cliente. Uma ação que promove vantagens para o } \\
\text { consumidor e comprometimento na gestão ambiental dos supermercados. }\end{array}$ \\
\hline D & $\begin{array}{l}\text { Acredita que a solução para o problema de uso, redução e extinção das sacolas plásticas esteja } \\
\text { na implementação de leis. }\end{array}$ \\
\hline E & $\begin{array}{l}\text { Nessa rede de supermercados, já foram adotadas campanhas que ofereciam descontos aos } \\
\text { clientes que levassem sua ecobag. No início, a campanha foi bem-sucedida, depois os clientes } \\
\text { voltaram a usar as sacolas plásticas, em virtude de sua reutilização para descartar os resíduos }\end{array}$ \\
\hline
\end{tabular}




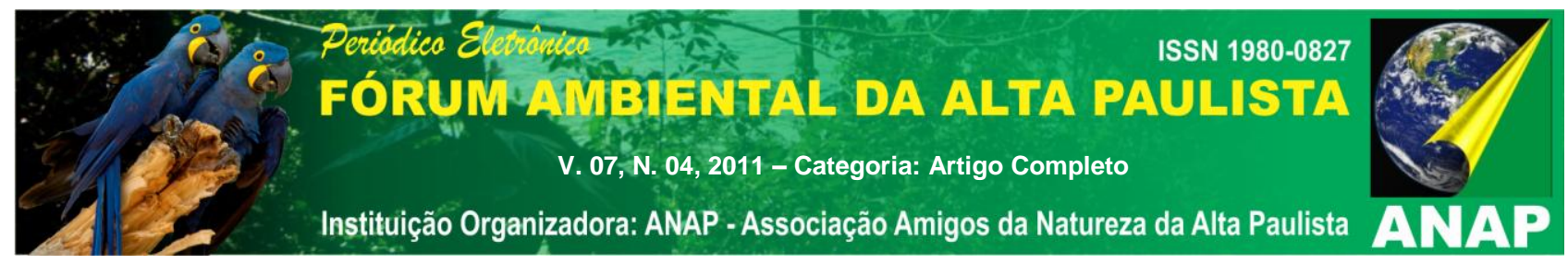

\begin{tabular}{|c|c|}
\hline & sticos, em face do custo para aquisição de sacos de lixo. \\
\hline $\mathrm{F}$ & $\begin{array}{l}\text { Se as pessoas não utilizassem as sacolas plásticas, poderia oferecer descontos sobre as } \\
\text { compras efetuadas. }\end{array}$ \\
\hline \multicolumn{2}{|r|}{$\begin{array}{l}\text { Alguns mercados, na tentativa de diminuir o uso, cobram pela distribuição das sacolas plásticas. É possível } \\
\text { prever o impacto dessa iniciativa perante os consumidores e os reflexos aos supermercados? }\end{array}$} \\
\hline A & $\begin{array}{l}\text { - redução de clientes e queda nos lucros. } \\
\text { Se houver a colaboração do poder público e de todos os supermercados da cidade, determinando } \\
\text { o valor a ser pago pela sacola plástica e ecobag, será possível a implantação de um projeto } \\
\text { desse tipo no município, com o objetivo comum de redução das sacolas plásticas. }\end{array}$ \\
\hline B & $\begin{array}{l}\text { - reclamações por parte dos clientes, mas não causaria redução dos clientes e nem afetaria as } \\
\text { vendas e os lucros do supermercado. } \\
\text { O gestor acredita, no entanto, que não seria aceitável no município, pois os clientes não } \\
\text { concordariam em ter esse custo a mais nas suas compras (por falta de conscientização). } \\
\text { Seria mais viável se houvesse a contribuição de todos os supermercados e o apoio do poder } \\
\text { público para a fixação de um valor único a ser cobrado pelas sacolas plásticas e a oferta de } \\
\text { ecobag com valores mais acessíveis. }\end{array}$ \\
\hline C & $\begin{array}{l}\text { - causaria uma redução nos clientes, afetando os lucros. } \\
\text { O gestor acredita que a campanha de redução é viável se houver a colaboração de todos os } \\
\text { supermercados, com o apoio do poder público, com o fornecimento de sacolas a preços } \\
\text { acessíveis, e, assim, diminuir o valor das mercadorias em consequência da redução dos custos } \\
\text { com sacolas plásticas. }\end{array}$ \\
\hline $\mathrm{D}$ & $\begin{array}{l}\text { - não causaria redução dos clientes e nem das vendas do supermercado. } \\
\text { Cobrar um valor para as sacolas plásticas desencadearia uma mudança de hábito nos } \\
\text { consumidores, impulsionando-os a optar por outras maneiras mais ecológicas para carregar suas } \\
\text { compras. Além disso, com a colaboração de todos os supermercados da cidade e do poder } \\
\text { público, seria mais fácil de conscientizar o cliente a diminuir o uso das sacolas plásticas e } \\
\text { substituí-las por ecobags. }\end{array}$ \\
\hline $\mathrm{E}$ & $\begin{array}{l}\text { - perda de clientes e redução nos lucros do supermercado. } \\
\text { Se todos os supermercados cobrassem um valor pelas sacolas plásticas, acredita que seria } \\
\text { possível sua implementação sem afetar os resultados, contudo campanhas como estas não } \\
\text { colaboram para a extinção das sacolas plásticas; apenas reduzem o seu consumo. Dependendo } \\
\text { da classe social do consumidor, os centavos que irá pagar a mais não farão a diferença em seu } \\
\text { orçamento, impactando apenas sobre pessoas com nível social mais baixo. }\end{array}$ \\
\hline $\mathrm{F}$ & $\begin{array}{l}\text { - causaria uma redução nos clientes, afetando os lucros. } \\
\text { Se todos os supermercados cobrassem pelas sacolas, não haveria problema. }\end{array}$ \\
\hline
\end{tabular}

Fonte: Dados da pesquisa, 2011.

Quadro 4 - Comprometimento e tendências gerenciais nos supermercados.

\section{Considerações finais}

Depois de realizada a pesquisa entre os consumidores e gestores do setor supermercadista e analisados os dados coletados, nota-se que a maioria dos consumidores e todos os gestores dos supermercados são conscientes dos malefícios que o plástico pode causar ao meio ambiente, quando descartado de forma inadequada. Assim, são favoráveis à redução e proibição da distribuição das sacolas plásticas nos supermercados. Além disso, entende-se que, independente do grau de instrução, os questionados possuem conhecimento da mobilização ambiental sobre o uso, redução e extinção das sacolas plásticas, embora o nível de conscientização em relação às atitudes 


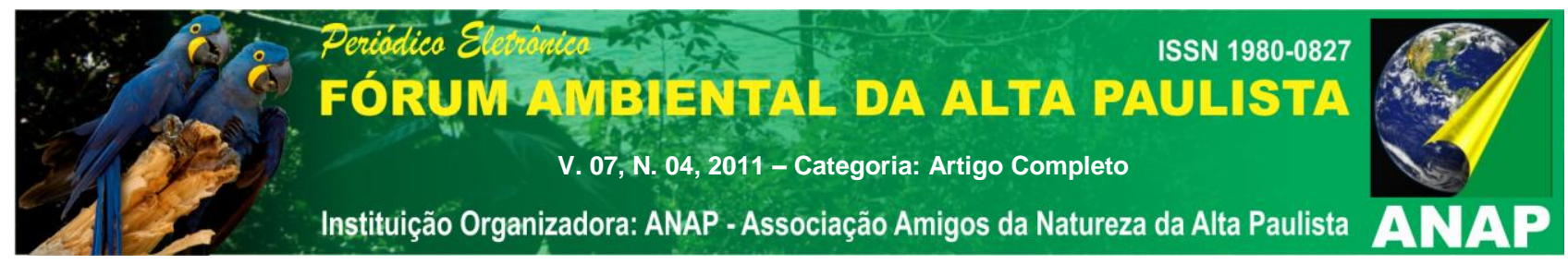

não tenha apresentado resultados significativos, tanto no grupo de consumidores, quanto no grupo de gestores dos supermercados.

Separar o lixo orgânico do lixo reciclável é uma ação de consciência realizada por muitos consumidores. Cerca de 54\% dos entrevistados separam o lixo doméstico, mesmo sabendo que não há coleta seletiva, pois afirmam que, ao realizarem essas iniciativas, estão conscientes de que resultarão em benefícios ao meio ambiente. As pessoas que não incorporaram esse hábito de separação justificam-se mencionando que não dispõem de tempo para desenvolver essas ações, no entanto a maior parte dos consumidores reclamou da falta de coleta seletiva no município.

Apesar de ser consciente e favorável à extinção das sacolas plásticas, a maioria dos entrevistados considera difícil visualizar o dia a dia sem elas. Não é difícil a disposição à mudança; é necessário encontrar meios alternativos para enfrentar essas transições, e os seres humanos possuem capacidade suficiente para adaptarem-se às mudanças de costumes e hábitos. Em síntese, destaca-se um bom nível de conhecimento, capacidade e disposição dos consumidores em relação à problemática das sacolas plásticas, além do comprometimento e tendências comportamentais dos consumidores, evidenciadas em intenções positivas quanto à adesão a leis e práticas de redução e extinção das sacolas plásticas. As iniciativas e atitudes apresentam, no entanto, baixo índice de conscientização dos consumidores quanto às práticas de sustentabilidade ambiental.

Os gestores dos supermercados demonstram possuir conhecimento e são favoráveis às ações de redução e extinção das sacolas plásticas, no entanto não apresentam ações (práxis) estruturadas e efetivas quanto à gestão desses recursos. Além disso, apresentam barreiras quanto ao comprometimento e tendências gerencias:

- estimam que são poucos os clientes favoráveis à extinção das sacolas plásticas;

- acreditam que a solução para o problema de uso, redução e extinção das sacolas plásticas depende da implementação de leis;

- campanhas que cobram pela distribuição das sacolas plásticas não colaboram para a sua extinção;

- para muitos consumidores, os centavos pagos a mais (na compra das sacolas plásticas) não fará a diferença em seu orçamento; e, 


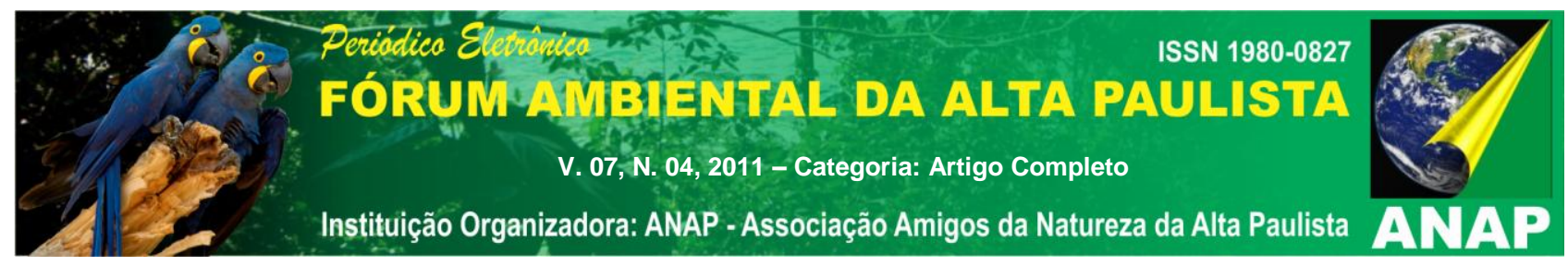

- é necessária a contribuição de todos os supermercados e o apoio do poder público para a fixação de um valor único a ser cobrado pelas sacolas plásticas e a oferta de ecobag com valores mais acessíveis.

Alguns gestores destacam pontos positivos na implementação de ações de redução e extinção das sacolas plásticas favoráveis aos consumidores e ao meio ambiente: um é o desconto do valor das mercadorias em consequência da redução dos custos com sacolas plásticas; o outro é a promoção da mudança de hábito dos consumidores, impulsionando-os a optar por outras formas, mais ecológicas, para carregar suas compras.

O estudo fornece, portanto contribuições e reflexões quanto à postura dos consumidores e dos gestores dos supermercados em face de uma problemática que está em crescente desenvolvimento, e na busca de soluções efetivas. Além disso, sugere-se a ampliação da pesquisa envolvendo outros agentes, como o Poder Público, na instituição de leis e apoio no processo de conscientização e efetividade na gestão socioambiental.

\section{Referências}

ABIEF - Associação Brasileira da Indústria de Embalagens Plásticas Flexíveis. Indústria do plástico divulga comunicado contra banimento das sacolas. Mai, 2011. Disponível em: http://www.abief.com.br/noticias. Acesso em 21 de maio de 2011.

ALBUQUERQUE, F. Sacolas plásticas: maioria aprova proibição. 2010. Disponível em: http://planetasustentavel.abril.com.br/noticias/maioria-populacao-brasileira-aprovaproibicao. Acesso em: 09 de março de 2011.

ALIGLERI, L.; ALIGLERI, L. A.; KRUGLIANSKAS, I. Gestão socioambiental: responsabilidade e sustentabilidade do negócio. São Paulo: Atlas, 2009.

BRASIL. Constituição Federal. Brasília. Senado Federal, 2010.

BRASIL. Lei no 12.305/2010 - Institui a Política Nacional de Resíduos Sólidos. Disponível em: http://www.planalto.gov.br/. Acesso em: 07 de março de 2011.

Câmera de Uberaba/MG. Disponível em: http://camarauberaba.mg.gov.br/site/noticias/. Acesso em: 21 de maio de 2011.

CRESWELL, J. W. Projeto de pesquisa. 3. ed. Porto Alegre: Artmed, 2010.

DALLA COSTA, F. Lei determina que sacolas plásticas orientem a separação de lixo em Porto Alegre/RS. Revista Sustentabilidade. May 18, 2010. Disponível em: http://www.revistasustentabilidade.com.br/. Acesso em: 20 de abril de 2011. 


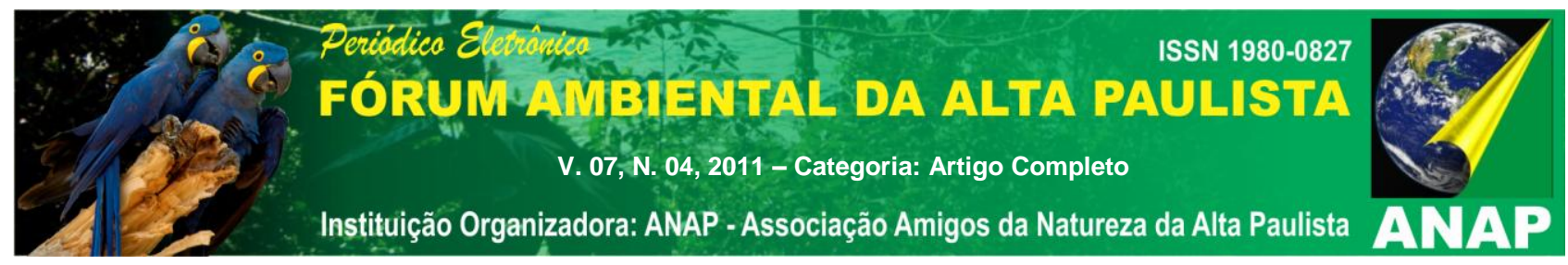

DIAS, S. A ilusão das ecobags. Revista Sustentabilidade. Aug 25, 2010. Disponível em: http://www.revistasustentabilidade.com.br/. Acesso em: 18 de maio de 2011.

FIGUEIREDO, M. A. G.; DEORSOLA, A. C. A questão da responsabilidade socioambiental na reciclagem de plástico no Rio de Janeiro. Revista Produção. vol. 21, no1: São Paulo. jan./mar-2011, Epub 28-Maio-2010.

FLICK, U. Introdução à pesquisa qualitativa. 3. ed. Porto Alegre: Artmed, 2009.

GIL, A. C. Como elaborar projetos de pesquisa. 4. ed. São Paulo: Atlas, 2002.

GRIPPI, S. Lixo: reciclagem e sua história. 2.ed. Rio de Janeiro: Editora Interciência, 2006.

MALHOTRA, N. K. Pesquisa em marketing. 4. ed. Porto Alegre: Artmed, 2004.

MATTAR, F. N. Pesquisa de marketing. 6. ed. São Paulo: Atlas, 2005.

MINISTÉRIO DO MEIO AMBIENTE. Sustentabilidade aqui e agora. Disponível em: http://www.mma.gov.br/estruturas/182/_arquivos/sustentabilidade_aqui_agora. Acesso em: 20 de maio de 2011.

OLIVEIRA, M. Excesso de sacolas descartáveis causa grandes danos. Disponível em: http://planetasustentavel.abril.com.br/noticia/ambiente/. Acesso em: 21 de maio de 2011.

PLANETA SUSTENTÁVEL. As sacolas plásticas devem ser substituídas? 2007. Disponível em: http://planetasustentavel.abril.com.br. Acesso em: 09 de março de 2011.

RIBEIRO, D. V.; MORELLI, M. R. Resíduos Sólidos: problema ou oportunidades. Rio de Janeiro: Editora Interciência, 2009.

ROQUE, L. P. Setor de plástico contra-ataca e lança campanha milionária para defender sacolinhas. Revista Sustentabilidade. Sep 09, 2009. Disponível em: http://www.revistasustentabilidade.com.br/. Acesso em: 05 de abril de 2011.

TACHIZAWA, T. Gestão ambiental e responsabilidade social corporativa. São Paulo: Atlas, 2009.

TACHIZAWA, T; ANDRADE, R. O. B. de. Gestão Socioambiental: estratégias na nova era da responsabilidade. Rio de Janeiro: Elsevier, 2008. 